\title{
NEM SÓ DE MAPAS SE FAZ A GEOGRAFIA: OS DIFERENTES NAS AULAS DE GEO
}

\author{
Not only maps make geography: the different ones in Geo classes \\ Rúbia Aparecida Cidade Borges* \\ * Mestre em Geografia - UFRGS - prof.rubiaborges@gmail.com.
}

Recebido em 15/08/2018. Aceito para publicação em 25/08/2018.

Versão online publicada em 03/09/2018 (http://seer.ufrgs.br/paraonde)

\begin{abstract}
Resumo:
Esse trabalho visa publicizar algumas discussões, realizadas em Dissertação de Mestrado, sobre alternativas às práticas homogeneizadoras de identidades na escola, de modo a, através das aulas de geografia, desnaturalizar discursos sobre as minorias e/ou grupos socialmente desfavorecidos (nessa escrita chamados de diferentes: mulheres, público LGBT, negros e refugiados), contribuindo para superar a subjetividade contrária à promoção dos Direitos Humanos e oportunizando a desconstrução de estereótipos presentes no "senso comum". Para tal, os ditos dos/as alunos/as de 9.․ano de escola pública municipal foram coletados, no ano letivo de 2016, e foram analisados com o apoio da bibliografia selecionada, a partir dos pressupostos dos Estudos Culturais e do ensino contemporâneo de Geografia Escolar.
\end{abstract}

Palavras-chave: Ensino de Geografia; Estudos Culturais; Direitos Humanos/minorias

\begin{abstract}
:
This work aims to publicize some discussions, carried out in Master Dissertation, on alternatives to the homogenizing practices of identities in the school, in order to denaturalize discourses about minorities and / or socially disadvantaged groups (in this writing called different: Women, the LGBT public, blacks and refugees), contributing to overcoming subjectivity contrary to the promotion of Human Rights and opportunizing the deconstruction of stereotypes present in "common sense". To that end, the students of the 9th year of municipal public school were collected in the year 2016 and were analyzed with the support of the selected bibliography, based on the assumptions of Cultural Studies and contemporary teaching Of School Geography.
\end{abstract}

Key-words: Geography Teaching; Cultural Studies; Human Rights / minorities

\section{Por que trabalhar Direitos Humanos e diferentes nas aulas de Geografia?}

Este artigo é resultado de uma dissertação de mestrado que trata da consideração dos Direitos Humanos e da problematização das demandas de minorias/grupos socialmente desfavorecidos, como temas pertinentes nas aulas de geografia, em turmas de 9.ㅇ ano, em escola pública municipal de Porto Alegre. O objetivo deste estudo foi levar os/as alunos/as a mobilizarem, questionarem e (re) construirem ideias, pensamentos e opiniões sobre essas minorias e grupos sociais, a partir da articulação entre o tema dos Direitos Humanos e os pressupostos curriculares e metodológicos da Geografia.

A partir dos ditos dos/as alunos/as nas atividades propostas em aula, juntamente com o referencial teórico pesquisado, procurou-se analisar quais as possibilidades desse componente curricular em potencializar práticas sociais a respeito de Direitos Humanos e dos diferentes. Nomeiase como diferentes os grupos sociais desqualificados ou desfavorecidos socialmente, por terem suas identidades distintas daquilo que se julga como norma e por terem inferiorizadas suas diferenças (nessa escrita: mulheres, público LGBT, negros/as e refugiados/as).

A opção por trabalhar esses temas, nas aulas de Geografia, veio da percepção de que, por estarem 
em lugares em vulnerabilidade social, muitos/as alunos/as têm seus direitos negligenciados e violados sistematicamente. Estão em permanente risco de violação de suas integridades físicas, não tem acesso à saúde digna, educação de qualidade, infraestrutura, moradias adequadas. Mesmo assim, também são agentes de violações de direitos ao fazerem bullying com colegas e ao compartilharem em redes sociais postagens racistas, machistas e homofóbicas, por exemplo. Pensar essas questões, em aula, aproxima a Geografia da vida dos estudantes, melhora a interação entre eles e os/as professores/as e, principalmente, cumpre na escola o papel de incentivar a cidadania, a busca por melhores condições de vida e a criticidade.

Para tal, realizaram-se diferentes propostas pedagógicas (aula expositiva, discussões a partir de vídeos, textos, charges, etc.) onde fossem mobilizados os ditos dos alunos sobre Direitos Humanos e os diferentes já citados. As aulas foram organizadas de modo a, inicialmente, mobilizar as ideias trazidas pelos alunos sobre cada tema para, posteriormente, promover a discussão dos assuntos frente a novas reflexões proporcionadas pelos textos, charges, vídeos, mapas e pelas propostas didáticas trazidas por mim para as turmas. As manifestações dos alunos, em aula e por escrito, são a base de análise da pesquisa aqui discutida.

\section{Diferentes como possibilidade de experimentação à Geografia Escolar}

Embora, em vários discursos institucionais, se diga "valorizar a diferença", percebe-se, fortemente, a presença as culturas hegemônicas nas propostas curriculares das escolas. A maneira de viver e conviver dentro de padrões (heteronormativos, androcêntricos, racistas) rejeitam, em geral, os desacordos como possibilidades legítimas de convivência. Dessa forma, as práticas escolares, seja através do currículo ou das metodologias, contribuem para o silenciamento e subestimação do papel dos grupos minoritários em quantidade e/ou poder. Assim, embora o acesso dos/as alunos/as e de suas diferenças seja universalizado pelas leis vigentes, as práticas, os currículos, os métodos, os materiais didáticos são pensados para só um público, para o "comum": heterossexual, branco, cristão e sem distorção idade-série, por exemplo.

A Geografia, como componente curricular obrigatório no Ensino Fundamental, tem sua parcela de contribuição no processo de normatização e desconsideração das identidades que fogem da dita normalidade, na medida em que atribui significados ao lidar diretamente com aspectos peculiares das sociedades, como elas se organizam, o que plantam, como tratam suas mulheres e suas crianças, como transformam o meio natural, etc. Esses significados, dados as coisas e as pessoas, podem estar a serviço da celebração da diferença e da desconstrução de discursos homogeneizantes ou, do contrário, podem ajudar a hierarquizar identidades e naturalizar silenciamentos.

De forma simplificada, a Geografia cumpre, na escola, o objetivo de propiciar o pensar e refletir o espaço geográfico nas suas diversas escalas, relacionando natureza e sociedades humanas, compreendendo relações regionais, locais e globais com a ajuda de imagens, leituras, fotos, vídeos e pesquisas. Ou ainda, pode se dizer que cabe à Geografia desenvolver um olhar crítico e questionador a respeito do espaço geográfico, permitindo que o aluno perceba que seu bairro, seu país, sua comunidade, etc., constituem-se na inter-relação entre o meio físico e as atividades humanas (com suas intencionalidades, especificidades e características econômicas, sociais e culturais) e que se modificam ao longo do tempo.

As aulas de Geografia devem oportunizar aos alunos/as a tomada de consciência das práticas sócio-espaciais suas e dos variados agrupamentos humanos, bem como a maneira como se espacializam coisas e fenômenos. Se fenômenos são espacializados em Geografia, se são possíveis espacializar mudanças climáticas, distribuições de vegetações determinadas, atividades econômicas, não seria possível espacializar deslocamentos de refugiados, tratamento dado aos gays nos diferentes pontos do planeta, a violência contra a mulher no Brasil, por exemplo? Kaercher (2014) destaca que a Geografia precisa dialogar com o mundo real, extrapolar o objetivo ingênuo de abastecer mentes com informações para utilização futura. Enfatiza a necessidade de uma geografia para a vida. 0 que 
seria mais real do que os estigmas, os preconceitos e as violações de Direitos Humanos que afetam esses alunos de escolas públicas?

Frente a uma consciência contraditória, a Geografia Escolar pode estar a serviço de uma pedagogia e de um currículo alternativo. Embora não vá mudar as estruturas que determinam a maneira como vivem os alunos, como constituem suas identidades, pode, modestamente, fazer alguma diferença na vida desses jovens, desestabilizando algumas de suas certezas e verdades, mobilizando novas considerações sobre si mesmos e seus pares, contribuindo para a desconstrução de hierarquias identitárias que desqualificam e silenciam pessoas.

Cavalcanti argumenta que "a Geografia é um conhecimento da espacialidade. Seu papel é explicitar a espacialidade das práticas sociais" (2012, p.150). Ao que, com mais razão, os Direitos Humanos são assunto da Geografia Escolar, pois não somente as práticas na construção de cidades, manufaturas, atividades econômicas, fronteiras e territórios podem ser trabalhadas por esse componente curricular, mas também as leis, os direitos, as relações interpessoais podem ser discutidas. Pode tratar da mulher que habita essas cidades e seus desafios, do gay que embora desenvolva atividades econômicas e tenha muitas outras identidades é reconhecido e discriminado pela identidade da sua sexualidade; do refugiado que procura romper com fronteiras e precisa se reencontrar e reconstituir nas territorialidades que encontra no local de destino.

0 ambiente físico, a preservação ambiental, as práticas sociais, por exemplo, são fruto desse jogo de poderes e os discursos vinculados. São constituídos por aqueles que, no mundo real, constroem os espaços estudados pela Geografia, por aqueles que, sentados nos bancos escolares, estudam esses conhecimentos e por aqueles que selecionam quais conhecimentos são pertinentes de serem estudados. Todos esses sujeitos exercem poder e resistência e são constituídos por discursos. 0 uso que fazem das e nas diferentes configurações espaciais, o que valorizam e dizem sobre elas também são atravessadas por essas relações.

\section{Breves repercussões sobre os diferentes nas aulas de Geografia: Direitos Humanos, o negro/a, a mulher, o público LGBT e os refugiados.}

A diferença, segundo Stuart Hall (2005) é o ponto que articula a formação do sujeito e de sua identidade. $\mathrm{Ou}$, colocando de outra forma, a identidade (de gênero, sexual, ética, religiosa, profissional ou quaisquer outras) se constitui através da determinação da diferença ou por meio dela. Assim, usando o exemplo do autor, se é mulher porque não se é um homem, se é branco porque não se é negro, etc. Embora, inicialmente, a identidade pareça ser facilmente definida como sendo aquilo que se é, Silva (2010) alerta que a identidade é "o ponto original relativamente ao qual se define a diferença" (p.75).

Segundo esse autor, esse pensamento demonstraria a tendência que temos em tomar aquilo que somos como norma ou referência para caracterizarmos e avaliarmos os diferentes, ou aquilo que não somos. A diferença ou identidade, não é, inocentemente, atribuídas aos indivíduos. Ambas, são o produto de disputas entre grupos situados, assimetricamente, em um jogo de poder; estão em disputa, traduzindo os desejos de diferentes grupos sociais, que buscam acesso privilegiado aos bens sociais e que fazem parte de relações mais amplas de poder.

Atravessados por esses discursos e por relações desiguais de poder, nas aulas de geografia, ao tratar de Direitos Humanos, a partir de textos, charges, palestras e atividades de escrita sobre o assunto, demonstraram em seus ditos, uma série de "sensos comuns" presentes na mídia e nas redes sociais, especialmente a ideia de que "Direitos Humanos é coisa de bandido" e associaram esse conceito às atividades criminosas e pejorativas. Outros alunos trouxeram a ideia da igualdade de tratamento e da liberdade de opinião e de ir e vir para definir o que são Direitos Humanos. Embora correta, essa visão é bastante limitada, pois desconsidera o papel dos Direitos Humanos na garantia do suprimento das necessidades básicas dos seres humanos (alimento, saúde, educação) e não 
incorpora o papel do Estado na garantia e manutenção desses direitos.

No entanto, verificou-se, a partir das intervenções pedagógicas, uma ressignificação do conceito de Direitos Humanos e a ampliação do sentido deste nos diferentes lugares, com uma aproximação do abstrato entendimento de direito com acontecimentos cotidianos dos estudantes. Então, mais apropriados da abrangência dos Direitos Humanos e de que eles devem/deveriam contemplar todos, conseguiram melhor perceber os direitos que lhes são garantidos, que lhes são negados e diferentes modalidades de violações relacionadas às especificidades de várias localidades do globo (nossa escola, Porto Alegre, alguns países e continentes). Assim, se de início, a ideia de Direitos Humanos era algo abstrato, distante, integrante do mundo das leis e normas, agora o tinham como sendo algo um pouco mais próximo das suas vidas. Essa maior proximidade legitima tanto o conceito, em si, de garantia de direitos, como a pertinência do trabalho com essa temática em sala de aula.

Tratando da questão das mulheres na sociedade, em escritas levantadas em atividades com mapas e textos nas aulas de geografia, os alunos determinaram que as mulheres ainda se encontram em uma situação de desprestigio na sociedade atual em relação aos homens e percebem as dificuldades imposta às mulheres pela questão do gênero, como as diferenças salariais, a dupla jornada de trabalho e a violência. As escritas dos alunos trouxeram, fortemente, o "senso comum" sobre o que é "ser mulher" e o que é "ser homem" na nossa sociedade, inclusive com a existência de atividades laborais típicas de cada gênero, dentro do discurso patriarcal que permeia nossas práticas sociais.

A distinção biológica foi usada como justificativa para que cada um desempenhe papéis sociais secularmente definidos, que permitem compreender e justificar as desigualdades sociais entre os sexos. A sociedade atual (globalizada, capitalista) continua transversalizada por uma cultura de submissão e violência junto às mulheres, que são intrínsecas a uma ordem patriarcal e androcêntrica (que entende o homem como hierarquicamente superior). Isso decorre de discursos sociais e de uma educação pautada no feminino como dócil, frágil, apaziguador, necessitado da "proteção" e da "condução" do homem em razão de sua debilidade e inferioridade física, emocional e cognitiva.

Sobre a violência contra as mulheres, embora cause indignação, é uma violência é relativizada em muitas falas, atribuindo à vítima uma co-participação no ato de violência, por ação ou omissão da mulher em algum aspecto que justificasse os episódios de agressão. Nos comentários de muitos meninos que reprovavam a agressão contra as mulheres, eles o faziam não por ser uma violação ao direito de integridade delas, mas por certo "cavalheirismo", uma noção de que não se bate em mulheres por serem "frágeis". Ou seja, é retirada da mulher a condição de sujeito de direitos, tornando-a como algo a ser cuidado pelos homens e, algumas vezes, em razão da associação de que aquela mulher agredida poderia "ser sua mãe, filha ou irmã". Dessa forma, são merecedoras dessa proteção àquelas meninas/mulheres com um comportamento esperado, como aquele percebido pelas mulheres de suas famílias, sendo que o mesmo cuidado não é dado para àquelas que estiverem em desacordo com aquilo que o senso comum diz não ser "comportamento de mulher direita".

Já nas escritas levantadas sobre a homofobia e suas percepções a respeito das identidades LGBT, ficou claro o constrangimento, principalmente dos meninos, em falar sobre o assunto, como se emitir opinião sobre isso pudesse rotulá-los como vulgarmente chamam, de "veados" e gays. De muitas formas, essa timidez, esse "silêncio sobre a diversidade sexual reflete uma forma produtiva do poder que regula o campo do enunciável" (RAUPP, 2015,p.119). Essa censura e esse silenciamento são formas produtivas de poder, pois não somente os negam, como controem e proliferam discursos. Ou, nas palavras de Foucault (2015, p.30) "não existe um só, mas muitos silêncios e são parte integrante das estratégias que apoiam e atravessam discursos.".

Os alunos, conforme se constatou em suas escritas, percebem o preconceito sofrido pelos homossexuais e declaram que é errado; inclusive condenam a violência contra os homossexuais, justificando que "ninguém tem direito de bater em ninguém por ser diferente." Mas se o gay não deve apanhar, também não precisa estar muito perto, como ficou claro nessas escritas. Conseguem perceber que um colega gay/lésbica ficaria triste e constrangido com xingamentos, mas demonstram que faz parte da sua afirmação de normalidade apontar traços de homossexualidade nos colegas. Não basta ser heterossexual, tem que parecer ser heterossexual e, nesse caso, ser homofóbico se faria 
necessário.

Sobre a identidade negra, quando perguntados se a situação do racismo está mudando no Brasil, alguns alunos disseram que a situação está melhorando, e usaram como exemplo as cotas raciais, que proporcionaria uma oportunidade de "subir na vida" aos jovens negros; outros alunos disseram que a situação está igual ou piorando, e citaram justamente as "cotas raciais" como um exemplo de discriminação, pois, segundo eles, deixaria subentendido que os "negros são menos capazes".

Essa questão da suposta falta de empenho dos/as negros/as e de certa "vitimização" da qual os/as negros/as são acusados ao buscarem direitos, denunciarem discriminações e apoiarem causas que lhes permitam concorrer com os brancos em condições mais justas, pode ser percebida nos ditos de alguns/as alunos/as. Com o discurso de que "no Brasil os direitos são iguais para todos" eles desconsideram a questão do racismo como algo institucionalizado em nosso país, retroalimentado por décadas de descasos e omissões do poder público para com violações de direitos dessas populações.

Todos, embora não se reconheçam como racistas, defendem que o Brasil é um país racista, dentro daquela constatação esquizofrênica da presença do fenômeno sem o agente executor. Essa aparente contradição repercute uma realidade presente na sociedade: admitimos que existe racismo, mas de alguma forma culpamos os negros pela situação pelo qual são vítimas, embora não consigamos explicar de onde tiramos essa opinião. Como diz Harari (2015, p. 151), "os preconceitos impregnaram a hierarquia imaginada em um nível ainda mais profundo da consciência humana".

Sobre os refugiados, considerando que existem haitianos na comunidade escolar, as respostas dos alunos e suas manifestações em sala de aula demonstram que a identidade do haitiano e sobrepõe a quaisquer outras (de homem ou mulher, pobre ou rico, negro ou branco), gerado pela falta de empatia para com aquele intruso na comunidade. Mesmo os negros colocam-se de forma superior à esses imigrantes, na ideia de que "além de negros, são refugiados. Na hierarquia das identidades encontram-se em posição mais desfavorável do que mulheres ou os negros, pois numa situação de igual pobreza, ainda enfrentam a dificuldade da cultura e do idioma. 0 corpo nasce do entrelaçamento entre a natureza e a cultura: questionados porque chamam os colegas de haitianos, alegaram que eles são diferentes e elencaram: eles são negros "mais pretos", vestem-se muito arrumados, as meninas adornam-se com laços e fitas nos cabelos muito bem penteados e são "muito educadinhos" e formais.

Ao tratar dos refugiados sírios e africanos que buscam chegar na Europa, não apareceram escritas de que os "refugiados tiram os empregos", por exemplo. Isso remete a questão da tolerância, que alguns defendem quando tratamos de diferentes e Direitos Humanos. Toleramos o diferente, toleramos o negro, o deficiente, o refugiado, o gay. No entanto, tolerar ainda é discriminar, pois existe uma hierarquia embutida nessa relação social: não os ofendemos, fazemos alguma caridade para eles e até podemos ser "amigos" deles, mas ainda mantemos um afastamento, pois somos o "normal". Assim, hipoteticamente, alguns alunos aceitam que os países abriguem refugiados, desde que não seja o seu país, que não morem em seu bairro, divida com eles seu ônibus e sua escola, etc. Por isso, a tolerância não é o objetivo a ser alcançado, mas sim um convívio social onde a diferença seja algo visto como salutar, positivo e até desejado.

\section{Um tema sem conclusão}

Trabalhar com Direitos Humanos, com valores sociais justos, com empatia e empoderamento é trabalhar mergulhado em utopia. Ser professor é ser utópico. Especialmente em épocas difíceis, de ataques e desmontes àquilo que consideramos certo e bom, a docência é um exercício de fé, pois "todo professor é um crente, ainda que ateu seja" (KAERCHER, 2014, p. 242). Então, é a utopia que ampara essa pesquisa: a esperança de que a educação e, quem sabe, a Geografia Escolar e minhas aulas possam, de alguma forma, ajudar meus alunos a buscar pelo que for melhor para si e suas famílias, através de um convívio respeitoso e solidário consigo e com o outro. Dito de outra forma, tenho fé de 
que a escola, além de lugar de construção de saberes e aquisição de habilidades, possa ser também palco de compreensão e expansão de possibilidades, ou ainda, espaço de liberdade de (re) construção de identidades e celebração de diferenças.

Podemos temperar o ensino da Geografia trazendo as minorias, os em desacordo com a norma, os que fogem da heteronormatividade, os não-brancos, os não-homens para as aulas, de modo a dar-lhes visibilidade. Pois, discutir Direitos Humanos serve, também, para sensibilizar, para que de tanto ser dito e discutido, as práticas de discriminação, injustiça e violência sejam, pouco a pouco, compreendidas como desumanas por boa parte da população.

Embora não seja possível mensurar as prováveis mudanças de entendimento e comportamento dos alunos em relação às temáticas trabalhadas, vejo méritos em simplesmente mobilizar seus préconceitos e preconceitos, possibilitando-os exercitar uma argumentação que supere o "porque sim" que cotidianamente utilizamos, para empregarem, ainda que de forma incipiente, relações entre suas opiniões e textos, vídeos, discussões apresentadas na disciplina de Geografia e em outros componentes curriculares.

É preciso considerar a validade da tentativa de não fazer da Geografia Escolar um fim em si mesma, mas antes uma Geografia como possibilidade de entendimento e, principalmente, de atuação no mundo. Extrapolar o acúmulo de informações, sob o risco de transformar nossas aulas em um elenco de curiosidades e informações isoladas sobre lugares e povos, como em um Discovery Channel pouco atrativo e de baixa qualidade e, assim, nos fazermos obsoletos. Ou, como nos fala Kaercher, fazermos uma Geografia Escolar que nos permita (...)" humanizar a Terra com uma espacialidade mais justa e fraterna que permita aos estratos mais deserdados não só saciarem a fome de pão, mas também de poesia e fantasia." (2014, p.254). A Geografia precisa, na escola, ter uma existência mais digna do que ser um repositório de curiosidades.

Para meus alunos, acredito que o percurso investigativo para o qual contribuíram agregou, a eles, a oportunidade de experimentarem o estranhamento em relação a si próprios e seus pares, sobre como se percebem, como entendem suas identidades e diferenças em relação à seus pares, que se deem conta das violações de direitos que submetem e ao qual estão submetidos enquanto jovens, meninos/meninas, negros/brancos, gays/heteros da periferia de Porto Alegre. Ao espacializar essas demandas, dão se conta de que o que sofrem não é só pelo que eles são, mas pela posição que ocupam no contexto social. E assim, melhorar suas vidas passa, principalmente, em modificar esse contexto.

Finalmente, o crescimento e a aprendizagem ocorrem no diálogo de homens e mulheres, adultos e jovens, comprometidos com a transformação das coisas em prol da melhoria da vida humana, da capacidade de criar e recriar. Acreditar nas pessoas, nos alunos, no potencial inerente a todos de se transformar é fundamental para uma Educação em Diretos Humanos. Por isso deve-se fazer a vigilância constante da nossa prática, daquilo que é transmitido nas entrelinhas da rotina escolar, na escolha dos conteúdos, na seleção daquilo que é dito, de como é dito e daquilo que é silenciado. Das coisas e pessoas que são vistas ou invisíveis no cotidiano da sala de aula.

\section{Referências}

ARÁN, M. Os destinos da diferença sexual na cultura contemporânea. Estudos Feministas. Florianópolis. jul-dez 2013.

BENEVIDES, Maria Victória. Cidadania e Direitos Humanos. Instituto de Assuntos Avançados da USP, São Paulo, p.1-11, 2015. Trimestral.

BORGES, Rúbia A. Cidade. Nem só de mapas de faz a Geografia: os diferentes nas aulas de Geo. Dissertação de Mestrado. Programa de Pós Graduação em Geografia: Universidade Federal do Rio Grande do Sul. Porto Alegre: 2017. 
BORRILLO, Daniel. A homofobia. In: LIONÇO, Tatiana; DINIZ, Debora (Org.). Homofobia e educação: um desafio ao silêncio. Brasília: Letras Livres, 2009.

BRASIL. Ministério da Educação. Secretaria de Educação Fundamental. Parâmetros curriculares nacionais: geografia. Brasília: MEC/SEF, 1998.

::Ministério da Educação. Secretaria de Educação Fundamental. Lei de Diretrizes e Bases da educação nacional. Brasília: MEC/SEF, 1996.

Preconceito e Discriminação no Ambiente Escolar. Brasília: Fundação Instituto de Pesquisas Econômicas - MEC/INEP 2009.

CANDAU, Vera Maria. Educação em Direitos Humanos: desafios atuais. In: SILVEIRA, Rosa Maria Godoy et al (Org.). Educação em Direitos Humanos: Fundamentos Teórico-metodológicos. João Pessoa: Ufpb, 2007.

CAVALCANTI, L. O ensino de geografia na escola. Campinas: Papirus, 2012.

DINIS, Nilson Fernandes. Homofobia e educação: quando a omissão também é signo de violência. Educar em Revista, Curitiba, v. 39, p.39-50, 2011.

DORA, Denise Dourado. Cidadania e Direitos Humanos: para todos ou para alguns?. Texto do Curso de Extensão em Educação em Direitos Humanos/UFRGS. Porto Alegre, 2015.

FILIZOLA, Roberto. Didática da geografia: proposições metodológicas e conteúdos entrelaçados com a avaliação. Curitiba: Base Editorial, 2009.

FISCHER. Rosa Maria. Foucault e a análise do discurso em educação. Cadernos de Pesquisa. Rio de Janeiro, n. 114, p. 197-223, 2001.

FOUCALT, Michel. Arqueologia do Saber. Rio de Janeiro: Forense, 2015.

HALL, Stuart. A identidade cultural na pós-modernidade. Rio de Janeiro: Dp\&a, 2005

HARARI, Yuval Noah. Sapiens: Uma breve história da humanidade. Porto Alegre: 2015.

JARDIM, Denise. Os Direitos Humanos dos imigrantes:reconfigurações normativas dos debates sobre imigrações contemporâneas no Brasil contemporâneo. Densidades, São Paulo, v. 14, p.68-85, dez. 2013.

KAERCHER, Nestor. Das coisas sem rosa uma delas é a pessoa: as geografias do Manoel e do Nestor na busca do bom professor. In: TONINI, Ivaine et al (Org.). O Ensino de Geografia e suas composições curriculares: uma introdução aos estudos culturais em educação. Porto Alegre: Mediação, 2014.

LOURO, Guacira. Gênero, sexualidade e educação: uma perspectiva pós-estruturalista. Petrópolis, RJ: Vozes,1997.

MAIA, Luciano Mariz. Educação em direitos humanos e tratados internacionais de direitos humanos. In: SILVEIRA, R. M. G. et. al. (Orgs.). Educação em direitos humanos: fundamentos teórico-metodológicos. João Pessoa: Editora Universitária, 2007. p. 85-101.

NELSON, Cary; TREICHLER, Paula; GROSSBERG, Lawrence (Org.). Estudos Culturais: uma introdução. In: SILVA, Tomaz Tadeu da. Alienígenas na Sala de Aula: uma introdução aos estudos culturais em educação. Petrópolis: Vozes, 1995.

ONU/Organização das Nações Unidas. Plano de Ação: Programa Mundial para a Educação em Direitos Humanos. Brasilia: Unesco, 2012.

.: Declaração Universal dos Direitos Humanos, ONU:1948.

RIBEIRO, Mara Rejane; RIBEIRO, Getúlio (Org.). Educação em Direitos Humanos e diversidade: diálogos intedisciplinares. Maceió: Edufal, 2012. 704 p.

RIOS, Roger. $O$ direito da antidiscriminação e a tensão entre os direitos à diferença e o direito geral de igualdade. Direitos Fundamentais e Justiça. Jan-Mar. 2012.

SANTOMÉ, Jurjo Torres. As culturas negadas e silenciadas no currículo. In: SILVA, Tomaz Tadeu da 
(Org.). Alienídenas na Sala de Aula: uma introdução aos estudos culturais em educação. Petrópolis: Editora Vozes, 1995.

SILVA, Tomaz Tadeu da. Documentos de Identidade: Uma Introdução às Teorias de Currículo. $3^{\circ}$ Edição. Editora Autêntica. 2010.

SILVA, Tomaz Tadeu da; HALL, Stuart; WOODWARD, Kathryn. Identidade e diferença: A perspectiva dos Estudos Culturais. Petrópolis: Vozes, 2007.

SIMON, Roger. A pedagogia como tecnologia cultural. In: SILVA, Tomaz Tadeu da. Alienígenas na Sala de Aula: uma introdução aos estudos culturais em educação. Petrópolis: Vozes, 1995.

TONINI, Ivaine. Identidades capturadas : gênero, geração e etnia na hierarquia territorial dos livros didáticos de geografia. 2002. 151 f. Tese (Doutorado) - Curso de Programa de Pós-graduação em Educação, Universidade Federal de Santa Catarina, Porto Alegre, 2002. Disponível em: <http://www.lume.ufrgs.br/handle/10183/3191>. Acesso em: 23 fev. 2015. 